University of Nebraska - Lincoln

DigitalCommons@University of Nebraska - Lincoln

\title{
Speciation and Quantitative Mapping of Metal Species in Microbial Biofilms Using Scanning Transmission X-ray Microscopy
}

\author{
James J. Dynes \\ McMaster University \\ Tolek Tyliszczak \\ Lawrence Berkeley National Laboratory \\ Tohru Araki \\ McMaster University \\ John R. Lawrence \\ National Water Research Institute, Saskatoon, Saskatchewan \\ George D. W. Swerhone \\ National Water Research Institute, Saskatoon, Saskatchewan \\ See next page for additional authors \\ Follow this and additional works at: https://digitalcommons.unl.edu/usdoepub \\ Part of the Bioresource and Agricultural Engineering Commons
}

Dynes, James J.; Tyliszczak, Tolek; Araki, Tohru; Lawrence, John R.; Swerhone, George D. W.; Leppard, Gary G.; and Hitchcock, Adam P., "Speciation and Quantitative Mapping of Metal Species in Microbial Biofilms Using Scanning Transmission X-ray Microscopy" (2006). US Department of Energy Publications. 33.

https://digitalcommons.unl.edu/usdoepub/33

This Article is brought to you for free and open access by the U.S. Department of Energy at DigitalCommons@University of Nebraska - Lincoln. It has been accepted for inclusion in US Department of Energy Publications by an authorized administrator of DigitalCommons@University of Nebraska - Lincoln. 


\section{Authors}

James J. Dynes, Tolek Tyliszczak, Tohru Araki, John R. Lawrence, George D. W. Swerhone, Gary G. Leppard, and Adam P. Hitchcock 


\section{Speciation and Quantitative Mapping of Metal Species in Microbial Biofilms Using Scanning Transmission X-ray Microscopy}

JAMES J. DYNES, ${ }^{\dagger}$ TOLEK TYLISZCZAK, TOHRU ARAKI, ${ }^{\dagger,}$ \# JOHN R. LAWRENCE, GEORGE D. W. SWERHONE, § GARY G. LEPPARD, "AND

A D A P P H T C HCOCK*, †

Brockhouse Institute for Materials Research, McMaster University, Hamilton, Ontario, Canada L8S 4M1, Chemical Sciences Division, Lawrence Berkeley National Laboratory, Berkeley, California 94720, National Water Research Institute, 11 Innovation Boulevard, Saskatoon, Saskatchewan, Canada S7N 3H5, and National Water Research Institute, P.O. Box 5050, Burlington, Ontario, Canada L7R $4 A 6$

A scanning transmission X-ray microscope illuminated with synchrotron light was used to investigate the speciation and spatial distributions of metals in a microbial biofilm cultivated from river water. Metal $2 p$ absorption edge signals were used to provide metal speciation (through shapes of the absorption spectra) and quantitative spatial distributions of the metal species. This paper presents sample data and describes methods for extracting quantitative maps of metal species from image sequences recorded in the region of the metal $2 p$ edges. Comparisons were made with biochemical characterization of the same region using images recorded at the $C 1 \mathrm{~s}$ and 0 1s edges. The method is applied to detailed quantitative analysis of ferrous and ferric iron in a river biofilm, in concert with mapping $\mathrm{Ni}$ (II) and $\mathrm{Mn}(\mathrm{II})$ species in the same region. The distributions of the metal species are discussed in the context of the biofilm structure. These results demonstrate that soft $X$-ray STXM measurements at the metal $2 p$ absorption edges can be used to speciate metals and to provide quantitative spatial distribution maps for metal species in environmental samples with $50 \mathrm{~nm}$ spatial resolution.

\section{Introduction}

Microbial biofilms cycle metals in the hydrosphere and lithosphere through a number of biogeochemical processes, including accumulation, transformation, and biomineralization (1), affecting metal toxicity and bioavailability. Many studies have identified that either the cell or extracellular polymeric substances (EPS) are involved in the biogeochemical processes. In certain microbial species the EPS is known to accumulate metals (2-5), concentrating metals by $4-5$ orders of magnitude in some systems (6). In addition, the

\footnotetext{
* Corresponding author tel: 905 525-9140 ×24749; fax: 905 5212773; e-mail: aph@mcmaster.ca.

${ }^{\dagger}$ McMaster University.

‡ Lawrence Berkeley National Laboratory.

${ }^{\S}$ National Water Research Institute, Saskatoon, Saskatchewan.

"National Water Research Institute, Burlington, Ontario.

\# Present address: Department of Physics, North Carolina State University, Raleigh, NC, 27695.
}

EPS has been shown to play a role as a template in the production of specific minerals (7) and to influence metal speciation $(8,9)$. In some instances, metals have a higher affinity for cellular binding sites (10), and biogenic minerals have been reported inside microbial cells (11).

Traditional methods to speciate and quantify metals in biofilms and biofilm components have been based on fractionation and extraction. Correlation of metals with specific biofilm components is possible but incorrect conclusions can be reached due to metal re-distribution, respeciation, and limited sensitivity (9) or to modification of the biofilm components. Analytical electron microscopies such as (scanning) transmission electron microscopy ((S)TEM) coupled with energy dispersive spectroscopy (EDS), $(8,9,12)$ are capable of mapping metals in biofilms. Although STEM-EDS is well suited to the determination of elemental composition, morphology, and crystallinity, as well as nanoscale localization, the requirement of dehydration and sectioning can create artifacts such as shrinkage and aggregation of particles. Further, chemical sensitivity is limited to elemental composition; metal speciation can only be inferred; and the spatial distribution of metals in biological entities is only visually correlated to morphologies and structures but not directly to chemical composition. Finally, at high spatial resolution, quantification can be an issue in dilute situations since the amount of material present in nanoscale deposits might not be detectable, even though higher sensitivity, nonspatially resolved techniques indicate its presence (12).

The reactivity of different biofilm components (i.e., cells, EPS) toward metals depends on the type and concentration of the metal, its chemical form (i.e., metal speciation), and on the biochemical characteristics of the biofilm components, which in turn depend on the microbial population (e.g., bacteria, algae, fungi). In situ speciation and quantitative spatial distributions of metals, in the context of the biofilm components, including biochemical information, is lacking in aquatic ecosystems. If available, such information would promote better understanding of biogeochemical processes, and the role that biofilms play in affecting metal toxicity and bioavailability.

Soft X-ray scanning transmission X-ray microscopy (STXM) $(13,14)$ in which chemical sensitivity is achieved through the near edge X-ray absorption spectrum (NEXAFS), is a technique which can examine "real world" samples in hydrated environments without fractionation and extraction, or sectioning, thereby avoiding artifacts associated with the separation, dehydration, and sectioning processes. STXM can provide quantitative maps of chemical species at environmentally relevant concentrations (i.e., $\mathrm{mg} / \mathrm{kg}$ ), with a spatial resolution of better than $50 \mathrm{~nm}(15-17)$. Full field soft X-ray transmission microscopy has been used to examine Pseudomonas putida biofilms (18). Lawrence et al. (17) used C 1s image sequences to quantitatively map the spatial distribution of macromolecules such as proteins, lipids, and polysaccharides in a river biofilm. Chan et al. (7) used STXM to show that microbially generated iron-oxyhydroxide filaments contain polysaccharides, suggesting that the polysaccharides are the mineral structure-directing component. It is possible to deduce not only oxidation state but ligand arrangement, and, in some cases, ligand identity from details of the metal 2p NEXAFS fine structure (19-21). Pecher et al. (22) used STXM and linear regression procedures to perform Mn speciation from selected areas on bacteria-produced nodules using the Mn $2 p$ absorption edge. Although quantitative chemical maps were not generated, relative amounts 
of $\mathrm{Mn}$ (II), Mn(III), and Mn(IV) in the spores were determined. The more oxidized species were found to be located outside the cell membrane. STXM at the Mn 2p edge was used to observe planktonic P. putida bacteria transform $\mathrm{Mn}^{2+}$ to $\mathrm{Mn}^{3+}$ and $\mathrm{Mn}^{4+}$ as a function of time (23). The distribution of the Mn oxidation states in the cell and EPS was quantified from selected regions with a linear regression fit to reference spectra normalized to the computed atomic absorption value in the Mn $2 \mathrm{p}$ postedge. Caulobacter crescentus bacteria and $\mathrm{Al}$ mineral particles were observed to be closely associated using the $\mathrm{C}$ and $\mathrm{Al} \mathrm{K}$-edges (24) but quantitative chemical maps were not generated. Rothe et al. (25) mixed Eu with a humic acid (HA) and used STXM to determine that the mixture segregated into zones with different optical densities and NEXAFS signatures, indicating that a number of different $\mathrm{Eu}-\mathrm{HA}$ complexes were formed.

The major objective of this work is to illustrate the techniques used to quantitatively map the spatial distribution of metals/metal species in situ in a complex biological sample using STXM, and to evaluate detection limits, precision, and accuracy of the quantification, as well as indicate some of the challenges of the analysis. We use the $\mathrm{O} 1 \mathrm{~s}$ and $\mathrm{C} 1 \mathrm{~s}$ edges to place the metal maps in the context of the biology and biochemistry of the biofilm, although only briefly as our intent in this paper is mainly to show the potential of STXM for correlating metals with the biochemical and morphological characteristics of the biofilm. To our knowledge, quantitative mapping of metals in biofilms by soft X-ray STXM has not yet been reported. In this work we used STXM to study a cultivated river biofilm which contained a variety of natural (Fe, Mn) and artificially (Ni) introduced metals. Following a description of our experimental and analysis procedures, the speciation and quantitative analysis of ferrous and ferric iron is presented in detail, after which we present the results of mapping $\mathrm{Ni}$ and $\mathrm{Mn}$ in the same area using the same procedures as used for the Fe mapping. Finally, we discuss the metal speciation and spatial distribution in the context of the biofilm morphology, biochemical information, and biogeochemical processes.

\section{Materials and Methods}

Sample Preparation. The methodology has been described in detail elsewhere $(17,26)$. In brief, a river biofilm was grown on a silicon nitride membrane (Silson Ltd., Northampton, UK) attached to the surface of removable polycarbonate slides in a rotating annular reactor (27). Natural river water (South Saskatchewan River, Saskatoon, Saskatchewan, Canada) collected in January and February, 2003 was used as inoculum, and as the sole source of nutrients. The basic chemistry of the river water was as follows: conductivity 450 $\mu$ mhos $\mathrm{cm}^{-1}, \mathrm{pH}$ 8.5, turbidity $2.3 \mathrm{NTU}$, total Kjeldahl N 24 $\mathrm{mg} \mathrm{L}^{-1}$, and total hardness $185 \mathrm{mg} \mathrm{CaCO}_{3} \mathrm{~L}^{-1}$. The water in the reactor was changed every 7 days throughout the 6 -week growth period. Methanol $\left(2 \mathrm{mg} \mathrm{L}^{-1}\right)$ was added weekly to the water as a supplemental carbon source. At the end of 6 weeks the silicon nitride membrane containing the biofilm was removed from the reactor and placed in a solution containing $\mathrm{NiCl}_{2}\left(1 \mathrm{mg} \mathrm{L}^{-1}\right)$ for $24 \mathrm{~h}$. The $\mathrm{Ni}$ exposure was performed since a goal of this study was to investigate the extent of bio-accumulation and localization of Ni over a relatively short exposure to a concentration similar to that of concern in contaminated sites. After rinsing with reactor water, a wet cell was made to prevent drying and thus maintain the integrity of the biofilm. The wet cell was made by aligning a second silicon nitride membrane on top of the wet biofilm and then sealing the silicon nitride sandwich with a combination of epoxy and grease. The sample was transported in a cooler via courier to the synchrotron and examined within 7 days. For the data in this study, the biofilm sample was still fully hydrated during the first sets of measurements (February, March 2003) but by the time of the final STXM studies (November 2004) it was an incompletely hydrated gel. The Fe $2 p$, Mn $2 p$, Ni $2 p$, O 1s image sequences were collected in Feb/March 2003 when the biofilm was fully hydrated. Metal $2 p$ spectra of the metalsrich region were recorded over a longer energy scale in Nov 2004 in order to improve quantitation. The edge details of the spectra from the dried sample matched those recorded from the fully hydrated sample. The sample was stored at 4 ${ }^{\circ} \mathrm{C}$ when not being examined by X-ray microscopy.

Reference compounds $\left(\mathrm{FeCl}_{2} \cdot 4 \mathrm{H}_{2} \mathrm{O}, \mathrm{FeCl}_{3} \cdot 6 \mathrm{H}_{2} \mathrm{O}, \mathrm{MnSO}_{4}\right.$. $\mathrm{H}_{2} \mathrm{O}$, and $\mathrm{NiO}$ ) were obtained commercially (Sigma-Aldrich), dissolved in unbuffered, deionized, distilled water, deposited on silicon nitride membranes, and air-dried before STXM analysis.

Scanning Transmission X-ray Microscopy and Data Analysis. X-ray imaging and spectroscopy were carried out at the Advanced Light Source using STXM microscopes (28) at beamlines 5.3.2 (29) and 11.0.2 (30). The metal 2p and $O$ $1 s$ absorption edge studies were performed on the STXM11.0.2 microscope. Metal 2p edge studies of reference compounds were performed on both microscopes. Supplementary C 1s and $\mathrm{O}$ 1s studies were performed on the STXM5.3.2 microscope. STXM was used analytically by acquiring NEXAFS spectra at a single location (point mode), recording the same line at a sequence of energies (line scan spectra mode), or by recording complete images at a sequence of energies (image sequence mode (31)). The raw transmitted signals were converted to optical densities (absorbance) using incident flux signals measured through regions of the wet cell devoid of biofilm. The microscope energy scale was regularly calibrated with secondary standards, typically sharp gas-phase signals. Fe 2p spectra recorded at different times were found to have shifts relative to each other of up to 0.5 $\mathrm{eV}$. The absolute energy scale was set by assigning the energy of the second peak in the $\mathrm{Fe} 2 \mathrm{p}_{3 / 2}$ signal to $709.8 \mathrm{eV}$, the value found when the spectrometer had been recently calibrated. We estimate the accuracy of this calibration to be $\pm 0.2 \mathrm{eV}$. Similarly, for $\mathrm{Ni}$ and $\mathrm{Mn}$ the first peak in the $2 \mathrm{p}_{3 / 2}$ signal was set to 853.0 and $639.8 \mathrm{eV}$, respectively; for $\mathrm{O}$ 1s the peak of the $\pi^{*}$ signal of protein was set to $531.7 \mathrm{eV}$.

The methodology for deriving quantitative component maps of the nonmetal and metal species is illustrated in detail for the Fe species in the biofilm. It involved spectral fitting of image sequences using two linear regression procedures: one called stack fit, the other called singular value decomposition (SVD) $(22,32,33)$. The stack fit procedure was used to derive spectra characteristic of each metal species in the biofilm, and to confirm the number of oxidation states present for each metal species. In addition to the spectra of the constituent chemical species, the stack fit procedure includes an energy independent constant which accounts for possible differences in the background levels of the reference and image sequence spectra. Initially reference spectra of pure compounds $\left(\mathrm{FeCl}_{2}\right.$ and $\left.\mathrm{FeCl}_{3}\right)$ were used. Threshold masking of the stack fit derived component maps was then used to identify and group signals from widely spaced pixels that had similar spectral characteristics. These internal spectra were placed on an absolute linear absorbance scale by adjusting the intensity to that of the reference compounds. The internal reference spectra were then used to derive the final quantitative component maps using SVD. SVD was used to avoid confusion between the nonmetal signal (a slowly varying featureless signal) and the constant term in the stack-fit algorithm. The residual signal, which is the difference between data and the fit, averaged over all energies, was used to evaluate the quality of the spectral fit. All data processing was carried out using aXis2000 (34). 

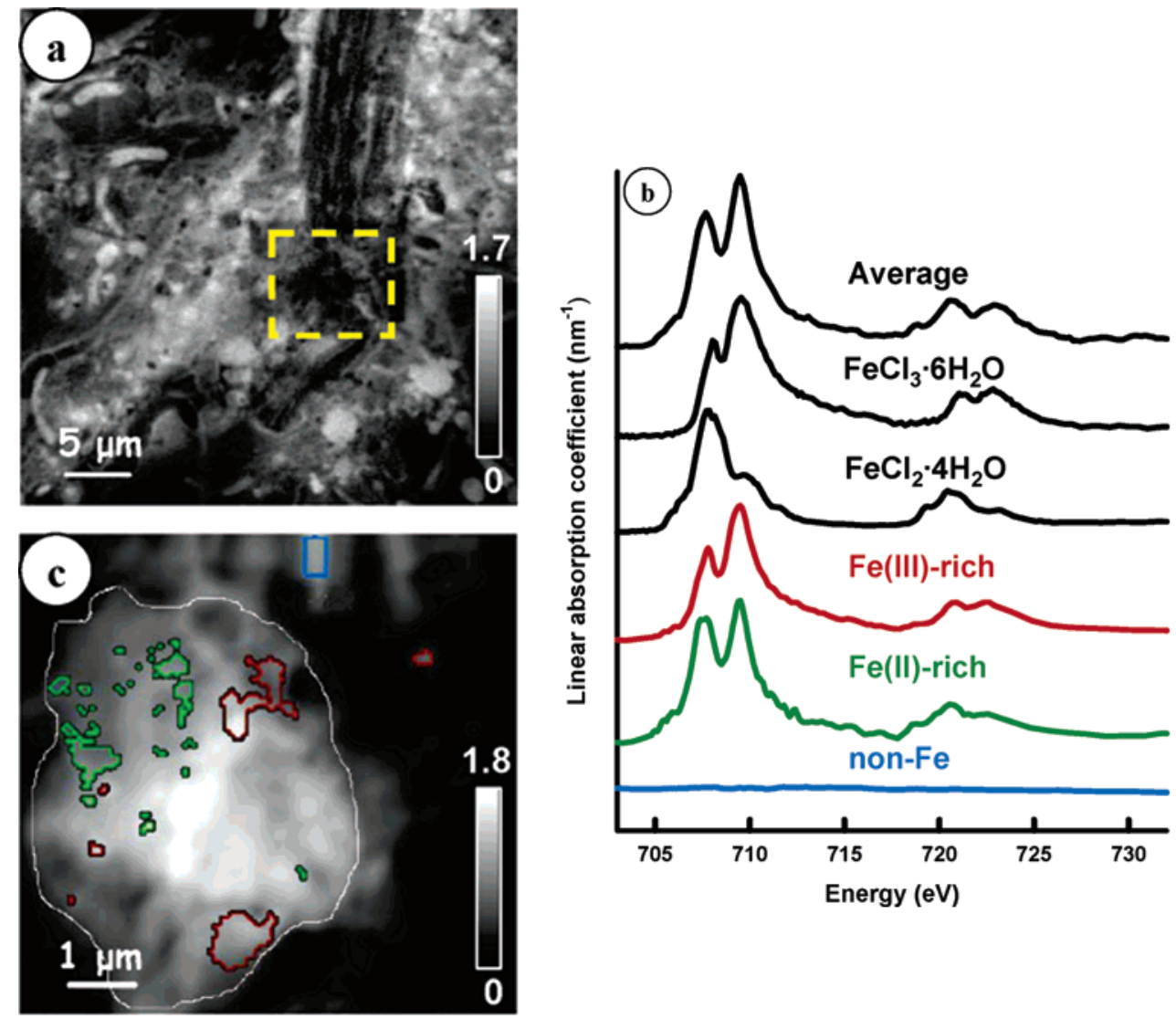

FIGURE 1. (a) Difference between optical density images at 288.2 and $282.0 \mathrm{eV}$ of a fully hydrated river biofilm. The area of the detailed metal $2 p$ edge studies is indicated in the yellow box. (b) Fe $2 p$ X-ray absorption spectra of $\mathrm{FeCl}_{3} \cdot 6 \mathrm{H}_{2} \mathrm{O}, \mathrm{FeCl}_{2} \cdot 4 \mathrm{H}_{2} \mathrm{O}, \mathrm{Fe}(\mathrm{III})$-rich, $\mathrm{Fe}(\mathrm{II})$-rich, non-Fe, and the average Fe 2p signal. (c) Average of 147 optical density images between 700 and $760 \mathrm{eV}$, in the region of the yellow rectangle in Figure 1a, with overlaid indicators of boundaries of regions from which the spectra were obtained (blue rectangle - non-Fe, green outline - Fe(II)-rich, red outline - Fe(III)-rich, white outline - average Fe $2 p$ spectrum). The gray scales indicate optical density.

\section{Results and Discussion}

The river biofilm examined in this study is a very rich bacterial-algal community with a variety of complex architectures and microbial compositions. These observations are in keeping with those obtained by confocal microscopies of similarly grown river biofilms (17). The area selected for detailed examination was chosen on the basis of large area survey difference maps $\left(\mathrm{I}_{709} \mathrm{eV}-\mathrm{I}_{702} \mathrm{ev}\right)$ which quickly identify areas of high metal content. A number of areas of the same sample have been studied and results on biochemical analysis and qualitative aspects of metal speciation have already been published $(30,32)$, or will be reported elsewhere. Here we focus on one specific area since it exemplifies issues relating to speciation and quantitation of metals in biofilms. Figure 1a shows a chemically selective image of this area, namely the difference between optical density (OD) images recorded at 288.2 and $282.0 \mathrm{eV}$. This difference signal primarily visualizes the microbial entities since it is dominated by the strong $\mathrm{C} 1 \mathrm{~s} \rightarrow \pi^{*}{ }_{\mathrm{C}=\mathrm{O}}$ band of protein at $288.2 \mathrm{eV}$, although there are weaker contributions from lipids and polysaccharides as well (17). Figure $1 \mathrm{c}$ is an expanded view of the metal rich region, recorded in the Fe $2 p$ region. This image and the associated Fe 2p spectra (Figure 1b) are discussed below. Note that radiation damage is apparent in Figure 1a, because the detailed metal mapping was performed prior to recording the $\mathrm{C}$ 1s region images. Notwithstanding the local damage, there is enough residual biochemical structure in the metal rich region and in adjacent regions to show that microbial activity was involved in forming the metal-rich structure.

Methodology and Fe Mapping. Speciation. Previous quantitative analysis by STXM dealt with systems where the exact chemical composition and number of components was known $(15,16)$, the components could be grouped into various classes of macromolecules (e.g., proteins, lipids) which were reasonably assumed to have similar NEXAFS spectra (17), or the spectra of reference metal species were used for quantitative charge state analysis (22). In this case, the exact chemical composition and number of major Fe species in the biofilm was initially unknown; thus, the selection of suitable Fe reference compounds and the number of species to use in quantitative analysis were problematic. To address this, the Fe $2 p$ image sequence was first examined manually by extracting spectra from various regions. It was evident that at least two different Fe species were present (data not shown but the spectra were similar to those derived using threshold masking of the component maps from the final analysis). The top trace in Figure $1 b$ is the average $\mathrm{Fe} 2 \mathrm{p}$ spectra over the whole region indicated by the white outline in Figure 1c. For Fe(II) compounds, the $2 \mathrm{p}_{1 / 2}$ and $2 \mathrm{p}_{3 / 2}$ bands start at lower energy than for Fe(III) compounds. Both Fe(II) and Fe(III) compounds show a double peaked $\mathrm{Fe} 2 \mathrm{p}_{3 / 2}$ signal but the relative intensities of the two peaks change with oxidation state. For $\mathrm{Fe}(\mathrm{II})$ compounds, the main $\mathrm{Fe} 2 \mathrm{p}_{3 / 2}$ peak is the first one, peaking at $708.0 \mathrm{eV}$. For Fe(III) compounds, the main Fe $2 p_{3 / 2}$ peak is the second one, peaking at $709.8 \mathrm{eV}$. In addition there are smaller and often very subtle changes in the Fe $2 p$ line shape for Fe compounds with different ligands or coordination geometry, but with the same oxidation state. On the basis of comparison to the Fe $2 p$ spectra of a range of reference compounds (20) (Figure S1), it was clear that both $\mathrm{Fe}(\mathrm{II})$ and $\mathrm{Fe}(\mathrm{III})$ species were present in the biofilm. 
The initial analysis was performed using spectra from two reference compounds, $\mathrm{FeCl}_{2} \cdot 4 \mathrm{H}_{2} \mathrm{O}$ and $\mathrm{FeCl}_{3} \cdot 6 \mathrm{H}_{2} \mathrm{O}$, which have Fe $2 p$ line shapes characteristic for most Fe(II) and Fe(III) species (20). To our knowledge the Fe 2p absorption spectrum of $\mathrm{FeCl}_{3} \cdot 6 \mathrm{H}_{2} \mathrm{O}$ has not been reported previously. The Fe $2 \mathrm{p}$ spectrum of $\mathrm{FeCl}_{2} \cdot 4 \mathrm{H}_{2} \mathrm{O}$ is similar to that reported previously (35). In addition to the two Fe chloride reference spectra, the stack fit included a reference spectrum without an Fe 2p signal (Figure 1b) that was extracted from a region in the biofilm (Figure 1c) where there was no detectable Fe signal. The resulting "Fe(II)-like" and "Fe(III)-like" component maps from this initial fit were then analyzed using threshold masking (33) to extract spectra corresponding to $\mathrm{Fe}$ (II)-rich and Fe(III)-rich regions. Analysis of the "constant" term component map or the residual did not indicate the presence of additional Fe species. Very similar $\mathrm{Fe}(\mathrm{II})$-rich and Fe(III)-rich spectra and component maps were derived using the two manually extracted Fe spectra instead of the two Fe chloride reference compounds, also indicating that two major Fe species could account for the spectral variance in the Fe $2 p$ image sequence. In fact, very similar $\mathrm{Fe}(\mathrm{II})$-rich and $\mathrm{Fe}$ (III)-rich spectra and component maps were derived using a number of different pairs of Fe(II) and Fe(III) species as reference spectra for the fitting. These statements do not imply that there are only two Fe species present in the biofilm; simply that we cannot differentiate if there are more than two, even though it is well-known that Fe 2p spectra can be quite sensitive to subtle aspects of oxidation state, ligand type, and coordination geometry (20). Moreover, the initial selection of $\mathrm{Fe}$ (II) and Fe(III) iron chloride reference compounds was based on convenience rather than environmental relevance. From this perspective any pair of Fe(II) /Fe(III) compounds would have provided a reasonable basis for this approach to the mapping, since they were used to "bootstrap" to the internal reference spectra ultimately used in the analysis.

Comparison of the Fe(II)-rich spectrum with the spectrum of $\mathrm{FeCl}_{2}$ (Figure 1b) indicates that although there is Fe present in the +2 oxidation state, the ratio of the 708 to $710 \mathrm{eV}$ peak differs. Attempts were made to decompose the Fe(II)-rich spectrum into multiple components with more "pure" Fe(II) and Fe(III) character. However, such attempts always resulted in unrealistic spectra and a less precise final analysis, based on the magnitude and structure of residual maps from trial fits. A number of pure Fe(II) compounds do exhibit significantly double peaked shapes at the $2 p_{3 / 2}$ edge, and there are even cases reported where the higher energy peak is more intense than the lower energy peak, such as $\mathrm{FeF}_{2}$ and $\mathrm{FeO}$ (36). It is unlikely that the Fe(II) species in the biofilm is $\mathrm{FeF}_{2}$. Some mixed valence compounds also exhibit a double peak shape at the $2 p_{3 / 2}$ edge. For example, pyrite reacted with $3 \%$ hydrogen peroxide for 5 min results in a mixture of different Fe valence states due to partial oxidation of $\mathrm{FeS}$ to $\mathrm{Fe}_{2}\left(\mathrm{SO}_{4}\right)_{3}$. This has an Fe $2 p$ spectrum (37) similar to that of Fe(II)-rich spectrum. Similarly, the $2 \mathrm{p}_{3 / 2}$ signal of pyrrhotite $\left(\mathrm{Fe}_{7} \mathrm{~S}_{8}\right)$ changed from a single peak at $\sim 708 \mathrm{eV}$ to a double peak when reacted with $\mathrm{FeCl}_{3}$ (38), giving rise to a line shape similar to that of the $\mathrm{Fe}(\mathrm{II})$-rich spectrum. A mixed valence state organic Fe complex ((Fe $\left.\left.{ }_{2}^{\text {III,II }}(\mathrm{bpmp})\left(\mu-\mathrm{O}_{2} \mathrm{CC}_{2} \mathrm{H}_{5}\right)_{2}\right)\left(\mathrm{BPh}_{4}\right)_{2}\right)$ (39) exhibits a similar double peak shape at the $2 \mathrm{p}_{3 / 2}$ edge but the pure valence compounds were similar to other pure valence compounds. Hence, comparison to Fe 2 p spectra from the literature suggests that the $\mathrm{Fe}(\mathrm{II})$-rich species is a mixed valence material but its exact identity could not be discerned. Spectra and image sequence mapping of other edges, such as C 1s and S 2p, would further assist in identifying the metal species.

Comparison of the $\mathrm{Fe}(\mathrm{III})$-rich spectrum with that of $\mathrm{FeCl}_{3}$ (Figure 1) indicates that the iron in these regions is predominantly in the +3 oxidation state. However, magnetite
$\left(\mathrm{Fe}_{3} \mathrm{O}_{4}\right)$ is a mixed valence $\mathrm{Fe}(\mathrm{II})-\mathrm{Fe}(\mathrm{III})$ compound with an Fe $2 p$ spectrum similar to those of Fe(III) compounds (40); we note that surface oxidation of the magnetite may have occurred and affected that published spectrum which was recorded with surface sensitive total electron yield detection. Thus, although the Fe(III)-rich spectrum is rather similar to that of pure Fe(III) species, it is possible that the material giving rise to that spectrum also has some mixed valence character. Note the dose used for metal mapping damaged the organic components. However, subsequent repeat measurements of the $\mathrm{Fe} 2 \mathrm{p}$ region gave identical results indicating the doses used were below those needed to reduce Fe(III) to $\mathrm{Fe}(\mathrm{II})$.

Quantitation. The natural concentration of $\mathrm{Fe}$ in the river water was $0.02-0.06 \mathrm{mg} \mathrm{L}^{-1}$ (41). The optical densities (ODs) of the $\mathrm{Fe} 2 \mathrm{p}$ signals in this region of the biofilm were in the $0.2-2$ range, an optimum level for linear conversion to thickness (nm). Quantitative analysis requires that the intensity scales of the Fe(II)-rich and Fe(III)-rich reference spectra be placed on an absolute linear absorbance scale. Absolute linear absorbance is the optical density per unit path length of a pure material of defined density, where the absorbance $(A)$, also called optical density (OD), is given by $A=\mathrm{OD}=-\ln (I / I \mathrm{o})$ where $I=$ transmitted intensity and $I \mathrm{o}$ $=$ incident intensity. Normally, for species with known composition, an absolute linear absorbance scale is established by adjusting the intensity scale of the reference spectrum to that of the computed elemental response outside the structured near edge region $(17,42,43)$. However, the exact identities and thus the elemental compositions of the $\mathrm{Fe}(\mathrm{II})$-rich and $\mathrm{Fe}(\mathrm{III})$-rich species are unknown. In the absence of a better choice, the intensity scales of the Fe(III)-rich and $\mathrm{Fe}$ (II)-rich spectra were set to match the computed elemental responses for $\mathrm{FeCl}_{3} \cdot 6 \mathrm{H}_{2} \mathrm{O}$ and $\mathrm{FeCl}_{2}$. $4 \mathrm{H}_{2} \mathrm{O}$, respectively. Systematic errors are likely associated with this procedure. Nevertheless, the spatial distributions and trends in the relative amounts of the Fe(II)-rich and $\mathrm{Fe}(\mathrm{III})$-rich species were similar for any pair of $\mathrm{Fe}$ (II)/ $\mathrm{Fe}$ (III) spectra used in the fitting. The analysis initially used different $\mathrm{Fe}(\mathrm{II}) / \mathrm{Fe}$ (III) compounds from the literature, including $\mathrm{FeCl}_{2}$, goethite $\left(\mathrm{Fe}_{2} \mathrm{O}_{3}\right)(35)$, pyrite (FeS), pyrite reacted with peroxide (37), $\left.\mathrm{Fe}_{2}{ }^{\mathrm{III}, \mathrm{II}}(\mathrm{bpmp})\left(\mu-\mathrm{O}_{2} \mathrm{CC}_{2} \mathrm{H}_{5}\right)_{2}\right)\left(\mathrm{BPh}_{4}\right)_{2}$ (39), and ferric and ferrous sulfate (39). When literature spectra were used instead of the iron chloride reference compounds, although the trends were similar, the precision of the quantification and the quality of the component maps were adversely affected.

While the strong resonance character of the metal $2 p \rightarrow$ 3 d transitions ("white lines") (19) greatly enhances analytical sensitivity, the correspondingly weak metal $2 p$ continuum provides a challenge to quantification. Measurement of reference spectra over a wide energy range helps accurately visualize the $2 p$ jump and thus facilitates accurate quantification. For this purpose we recorded the spectra of the iron chloride reference compounds over a very wide energy range (Figure S2 in the Supporting Information). The intensity scale of the non-Fe spectrum was set to match the average preedge signal level of the Fe-rich spectra. Using reference spectra with absolute linear absorbance scales provides absolute thickness scales for the component maps of each species and, by summation, a map of the total sample thickness.

The quantitative Fe(II)-rich, Fe(III)-rich, and non-Fe spectra were used in the SVD procedure (33) to derive quantitative component maps which are displayed in Figure $2 \mathrm{a}-\mathrm{c}$. The gray scale of each component map indicates the quantitative thickness (in $\mathrm{nm}$ ) of that species. Figure $2 \mathrm{~d}$ displays the spatial correlation of the three mapped species as a color-coded composite map, with red indicating the $\mathrm{Fe}(\mathrm{III})$-rich species, green indicating the Fe(II)-rich species, and blue indicating the non-Fe species. Note, the stack fit procedure gave component maps with the same spatial 

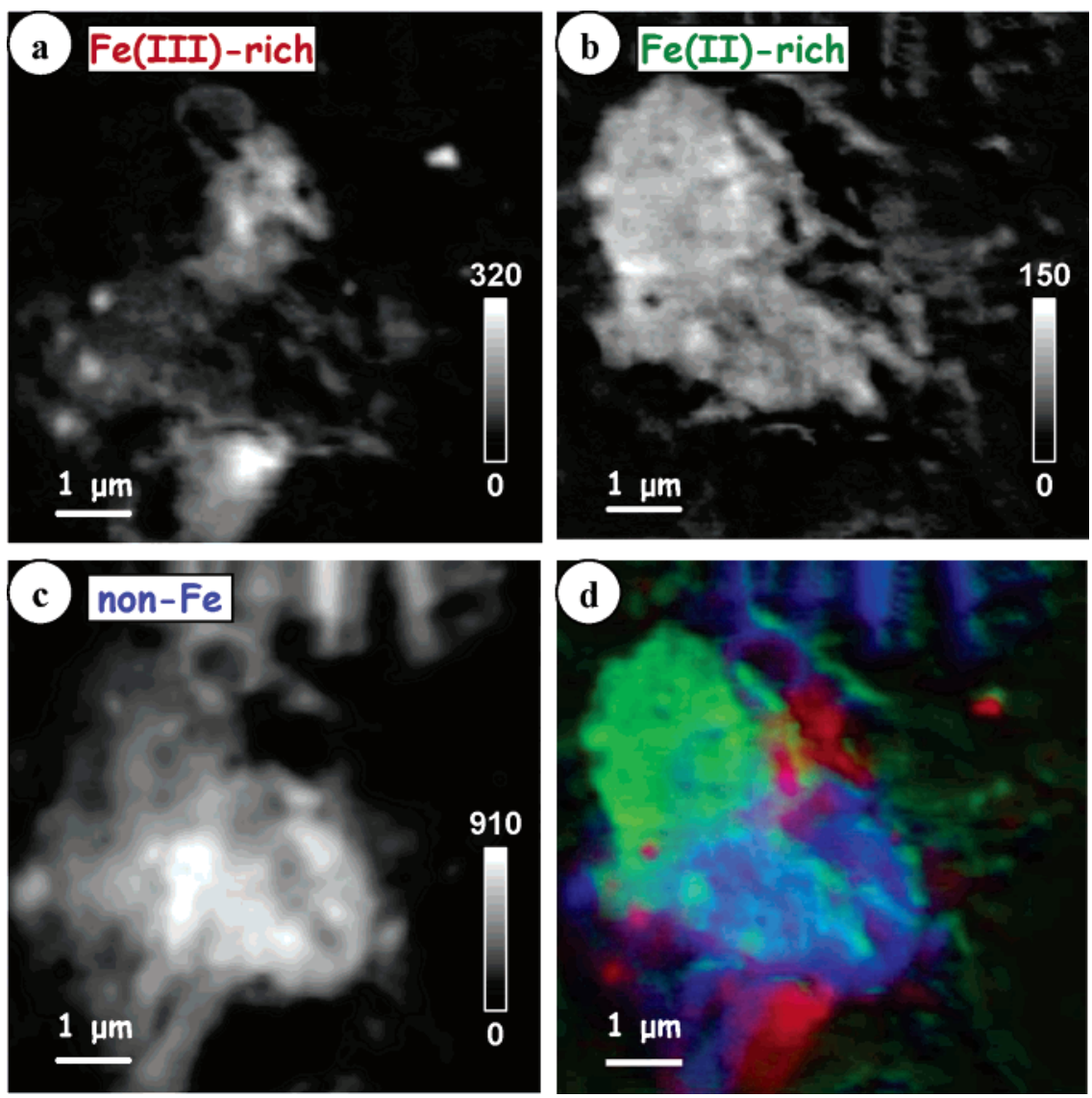

FIGURE 2. Component maps for (a) Fe(III)-rich (b) Fe(II)-rich, and (c) non-Fe species, derived by singular value decomposition (SVD) of an Fe $2 p$ image sequence to the three derived reference spectra (Figure 1). On the basis of the Fe 2p spectra, the Fe(II)-rich and Fe(III)-rich component maps are most likely that of a mixed valence Fe(II, III) species and a single valence Fe(III) species, respectively. (d) color composite (rescaled; red, Fe(III)-rich, green, Fe(II)-rich, blue, non-Fe component maps). Examples of SVD fits to the spectra of selected areas are presented in Figure S3; fits to single pixels are given in Figure S4. The gray scale indicates quantitative thickness (nm). The area studied is indicated in the yellow box in Figure 1a.

distributions and similar quantitative scales as the SVD procedure, giving credence to the methodology used to quantify the metals in the biofilm. The results are very likely to have large systematic errors but they are probably valid within a factor of 2 . The precision (statistical fluctuation) is of the order of a few percent, and thus the uncertainties in the absolute thicknesses of each component are mostly associated with systematic errors, such as use of incorrect elemental compositions in setting the reference spectral intensities.

The Fe(II)-rich and Fe(III)-rich component maps differ dramatically. There is little spatial overlap of the two species, as indicated by the relatively pure red and pure green coloring in most areas of the color composite (due to the individual color scaling, regions with 1-part Fe(II)-rich and 2-parts Fe(III)-rich would appear yellow in Figure 2d). There are some very localized "hot spots", $100-300 \mathrm{~nm}$ in size, with an Fe(III)-rich or Fe(II)-rich contribution 3-4 times larger than the Fe level in surrounding areas. The average thickness of the Fe(II)-rich, Fe(III)-rich, and non-Fe components, in areas where the component is present, is 0.04(3), 0.07(5), and 0.3(2) $\mu \mathrm{m}$, respectively. The cited uncertainties are associated with pixel-to-pixel variations due to inhomogeneous spatial distributions. The statistical uncertainty (pixel-to-pixel variation in uniform regions of the maps) is $\sim 2 \%$. It is apparent that the non-Fe components, which are attributed to the biofilm (e.g., cells, EPS, frustules), are considerably thicker than the Fe components in most areas.

Consideration of the amount of Fe components relative to non-Fe components helps explore the relationship of Fe species and microbiology. The thickness maps were converted to "concentration" maps (vol. \%), by dividing each component map by the sum of all three component maps. These concentration maps are shown in Figure 3. The minimum thickness of the sample over the area examined was $55 \mathrm{~nm}$. The two Fe species occur in, or adjacent to, areas with large amounts of biofilm. Some Fe(III)-rich signal occurred in areas apparently devoid of biofilm as indicated by the coincidence of the holes in the non-Fe fraction with the spots of strongest Fe(III)-rich signal in the Fe(III)-rich fraction. No such correlation exists for the Fe(II)-rich species, indicating that the Fe(II)-rich species is always associated with the biofilm. In some regions there are both Fe(III)-rich and $\mathrm{Fe}(\mathrm{II})$-rich species, while in most areas only one or the other species dominates. Even though the Fe $2 p$ signal is very strong, the total amount of iron species present (when integrated over the full area imaged) is small relative to the total biofilm thickness of about one micrometer.

The evaluation of the precision, accuracy, and detection limits of this analysis is discussed in detail in the Supporting Information. The amplitude of the residual is everywhere less than $0.09 \mathrm{OD}$, which is small relative to the total optical density $(0.2-2$ OD) (Figure S3a). The spectrum of pixels with large values in the residual map was found to deviate mostly in the shape of the underlying non-Fe signal, and not in the shapes of the Fe(II)-rich or Fe(III)-rich signals. This indicates that no significant Fe 2p signal was missed. To check that the derived $\mathrm{Fe}(\mathrm{II})$-rich and $\mathrm{Fe}(\mathrm{III})$-rich $\mathrm{Fe} 2 \mathrm{p}$ spectra are a good representation of the Fe species in the biofilm, the fit in the energy domain was examined. The spectral fits of Fe- 


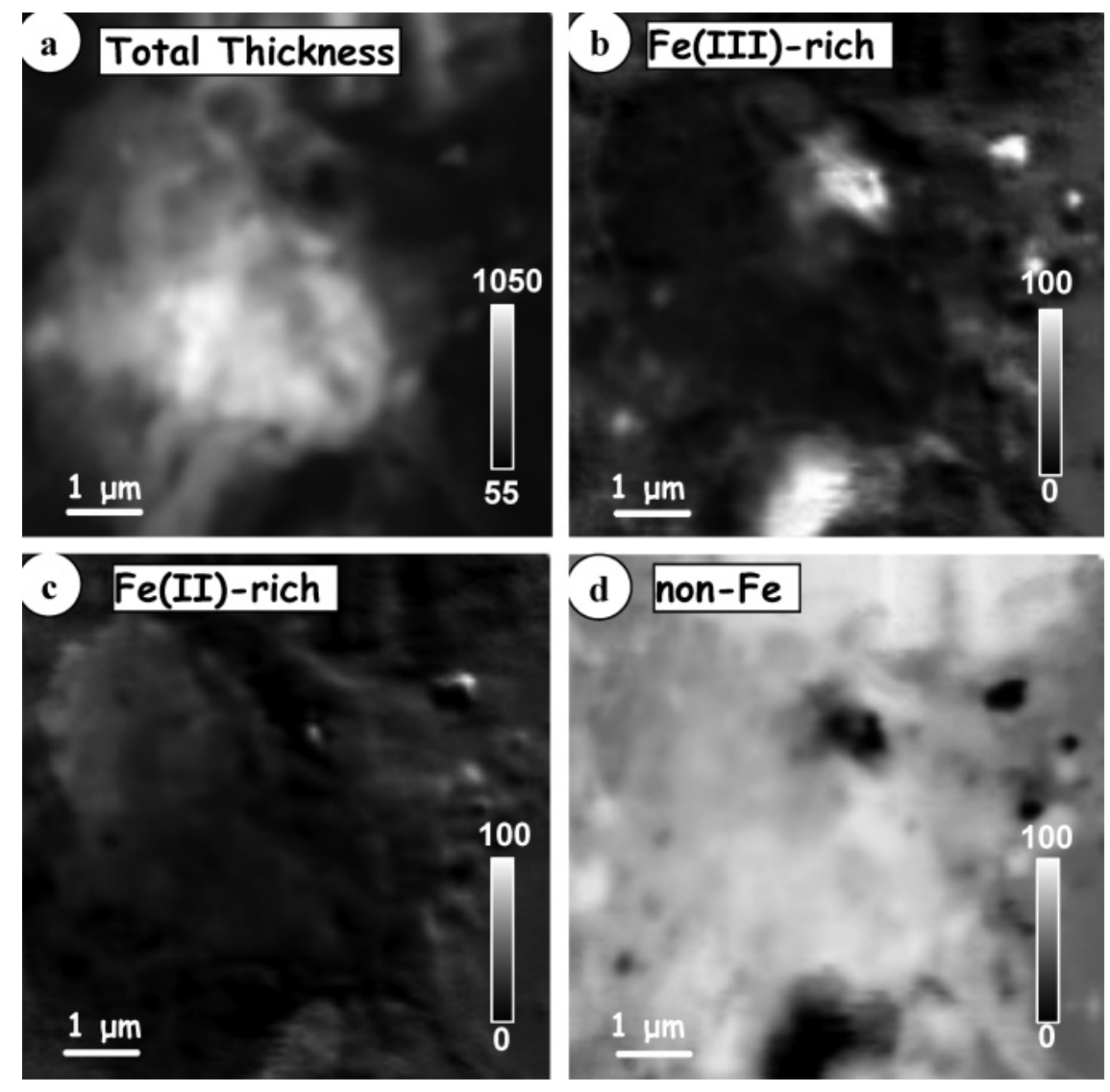

FIGURE 3. (a) Total thickness of the biofilm obtained by summing the three component maps (Figure 2). The gray scale indicates thickness (nm). (b) Concentration or relative thickness of Fe(III)-rich species, derived by ratioing the Fe(III)-rich component map to the total thickness of the biofilm. (c) Relative thickness of Fe(II)-rich species. (d) Relative thickness of non-Fe species. The area studied is indicated in the yellow box in Figure 1a. The gray scale $(b-d)$ indicates percent of total thickness.

rich pixels (Figure S3c, S3d) are of high quality. On the basis of the statistical precision of single pixel spectra (Figure S4), the detection limit in the present measurements was estimated to be $\sim 10^{-17}$ mole $\mu \mathrm{m}^{-3}$ Fe or $\sim 50 \mathrm{~g}(\sim 1$ mole $)$ $\mathrm{Fe} / \mathrm{kg}$ dried weight biofilm. This can be compared to a detection limit of $10^{-20}$ mole $\mu \mathrm{m}^{-3}$ or $\sim 50 \mathrm{mg}(\sim 1 \mathrm{mmol})$ $\mathrm{Fe} / \mathrm{kg}$ dried weight biofilm for spatially resolved X-ray excited, $\mathrm{X}$-ray fluorescence (XRF) cited for Fe in single cells (44). As outlined in the Supporting Information, we estimate that a detection limit in STXM similar to that of XRF could be obtained with longer dwell times and by combining signals from potentially widely spaced pixels based on similarity of their spectra.

$\mathrm{Ni}$ and Mn Mapping. Ni and Mn were also mapped in exactly the same area of the biofilm as that of the Fe mapping. Spectral characterization and quantitative mapping of these species was carried out using the same methodology described above for Fe. The natural Ni concentration of the river water is $1-2 \mu \mathrm{g} \mathrm{L}^{-1}$ (41). Thus, the most likely source of $\mathrm{Ni}$ in the biofilm is from the intentional exposure of the biofilm to $1 \mathrm{mg} \mathrm{L}^{-1} \mathrm{NiCl}_{2}$ in the last day prior to sealing the sample. The spectra extracted from different regions of the $\mathrm{Ni} 2 \mathrm{p}$ image sequence were similar, and the stack fit analysis confirmed that there was only one major $\mathrm{Ni}$ species present in the biofilm. Comparison of the Ni spectrum derived from the biofilm with that recorded from $\mathrm{NiO}$ (Figure 4a) (the latter matches that in the literature (19)) indicates the Ni was in the $\mathrm{Ni}$ (II) oxidation state. Figure $4 \mathrm{~b}$ presents the quantitative map of the spatial distribution of $\mathrm{Ni}$ in the biofilm, derived from an SVD analysis of the Ni 2p image sequence using as references the internal $\mathrm{Ni}$ spectrum, derived by threshold masking and placed on a linear absorption scale set by the long range $\mathrm{NiO}$ data, and the smoothed non-Ni spectrum extracted from a region with no detectable $\mathrm{Ni}$. The maximum thickness of $\mathrm{Ni}$ in the biofilm is $16 \mathrm{~nm}$. On average the Nicontaining regions have only $3-4 \mathrm{~nm}$ of $\mathrm{Ni}$. Ni is detectable in single pixel spectra at the sub-1-nm level. This is much lower than the lowest concentration at which the Fe species were detected (Figure 2).

The natural concentration of $\mathrm{Mn}$ in the river water was 0.01-0.02 $\mathrm{mg} \mathrm{L}^{-1}$ (41). The spectra extracted from different regions of the Mn 2p image sequence were similar, and the stack fit analysis confirmed that there was only one $\mathrm{Mn}$ species present in the biofilm. Comparison of the biofilm $\mathrm{Mn}$ spectrum with that recorded from $\mathrm{MnSO}_{4}$ (Figure $4 \mathrm{c}$ ), and those of $\mathrm{Mn}(\mathrm{II}), \mathrm{Mn}(\mathrm{III})$, and $\mathrm{Mn}(\mathrm{IV})$ species reported in the literature $(22,45)$ (Figure S5), indicates that the Mn was in the $\mathrm{Mn}$ (II) oxidation state. The $\mathrm{MnSO}_{4}$ spectrum produced in this study was similar to that from the literature (46). Figure $4 \mathrm{~d}$ presents the quantitative map of the spatial distribution of Mn in the biofilm. This was derived from an SVD analysis of the Mn 2p image sequence using as references the internal Mn spectrum, derived by threshold masking and placed on a linear absorption scale set by the long-range $\mathrm{MnSO}_{4}$ data, and the smoothed non-Mn spectrum, extracted from a region with no detectable Mn. The Mn thickness is intermediate between those of $\mathrm{Ni}$ and $\mathrm{Fe}$, peaking at a thickness of $\sim 30$ $\mathrm{nm}$, but with an average thickness of $10 \mathrm{~nm}$. Figure $4 \mathrm{e}$ contains a color-coded composite of the $\mathrm{Ni}$ and $\mathrm{Mn}$ component signals (the red and blue color scales are set to encompass the full thickness range so this represents position but not absolute signals). The Mn and Ni spatial distributions are very similar to each other, and quite different from that of either Fe species mapped. Interestingly, the ratio of the $\mathrm{Ni}$ and $\mathrm{Mn}$ mapped signals (Figure $4 \mathrm{f}$ ) is quite uniform $(\sim 2)$, with a few Mn-rich or Ni-rich hot spots. 

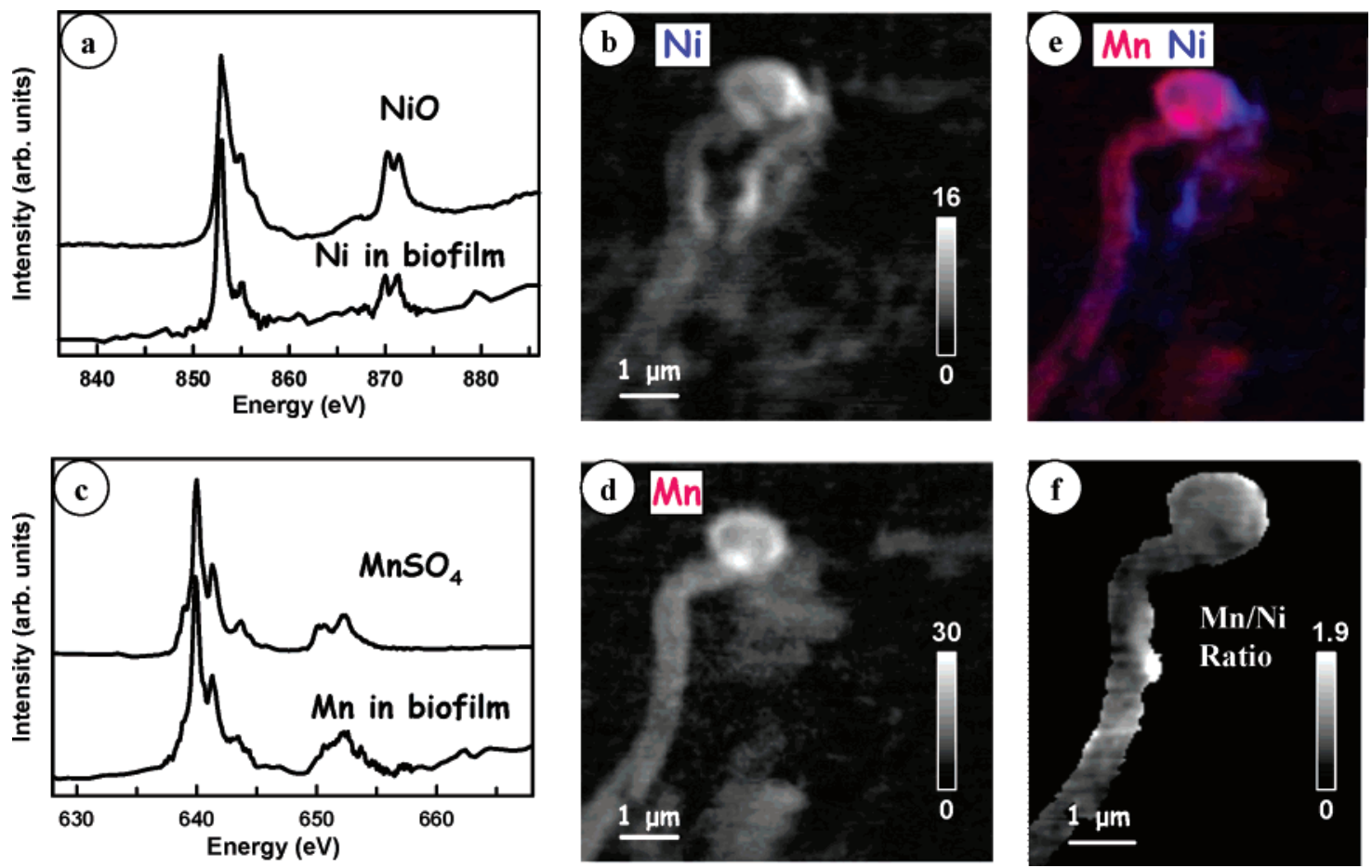

FIGURE 4. (a) Ni $2 p$ spectrum derived from the biofilm compared to that of NiO. (b) Ni component map derived by SVD of the Ni $2 p$ image sequence. (c) Mn 2p spectrum derived from the biofilm and that for $\mathrm{MnSO}_{4}$. (d) $\mathrm{Mn}$ component map derived by SVD of the Mn $2 p$ image sequence The gray scales indicate component thickness $(\mathrm{nm})$. (e) Color coded composite of the $\mathrm{Ni}$ (blue) and Mn (red) component maps (rescaled). (f) Ratio of the Mn and Ni signals. A mask was applied to exclude regions with negligible Mn or Ni signal. The area studied is indicated in the yellow box in Figure 1a.

The maximum thicknesses in the non-Fe, non-Ni, and non-Mn component maps were 900, 600, and $800 \mathrm{~nm}$, respectively; however, the average thickness of each component, in areas where the component is present, is $0.3(2)$, $0.2(1)$, and $0.3(2) \mu \mathrm{m}$, respectively. Comparison of the nonmetal maps (see Figure 2 for the non-Fe; those for Ni and Mn are not shown) showed very similar structures and thickness distributions, indicating the analyses of the three different edges model the nonmetal components in a similar way. The relatively similar results for three nonmetal maps gives credence to the validity of the metal component maps since the variation among the nonmetal maps is a measure of systematic errors in setting the intensity scales.

O 1s Image Analysis and Spectra. Further information about the species present in the sample was provided by analysis of an $\mathrm{O}$ 1s image sequence of a region which included not only the metal mapped area (Figure 1c) but also its surroundings (Figure 1a). Figure 5a displays the optical density image at $531.7 \mathrm{eV}$. Five distinct $\mathrm{O}$ 1s spectra were required to fully explain the $\mathrm{O} 1 \mathrm{~s}$ spectral variance in the region studied; the spectrum of water is also included for reference, although its contribution to the other spectra has been removed since an adjacent region of the sample, without biofilm, was used as the Io signal. Figure $5 \mathrm{~b}$ shows five spectra extracted from the image sequence in the color coded areas indicated in Figure 5a. These turned out to be the spectra of relatively pure single species. Those of lipid, protein, and polysaccharide are assigned based on comparison to reference spectra of pure materials (unpublished results). The spectrum for $\mathrm{SiO}_{2}$ was taken from the diatom frustule, known to be composed of silica (47). The spectrum labeled "oxide" in Figure 5a was attributed to that of an inorganic, possibly metal, oxide based on comparison to reference compounds $(38,48)$. The spatial distribution of the oxide component derived from the $\mathrm{O} 1 \mathrm{~s}$ image sequence (not shown) differs from that of the Fe species derived from the Fe $2 p$ absorption image sequence (Figure 2). In particular, the $\mathrm{O}$ 1s signal of this oxide was predominantly found in small localized areas that lie outside of the metal mapped area. The mismatch in oxide and Fe spatial distributions indicates that the Fe species in the biofilms are not primarily inorganic oxides. The $\mathrm{O} 1 \mathrm{~s}$ spectrum in the region where strong Fe(II)-rich signal was detected is primarily that of polysaccharides. This suggests that the Fe(II)-rich species was organically bound. The O $1 \mathrm{~s}$ spectrum in the region where strong Fe(III)-rich signal was detected is also primarily polysaccharides. However, the organic material was considerably thinner in the Fe(III)-rich than in the Fe(II)-rich region. Given that the Fe(III)-rich levels are typically $2-3$ times larger than the Fe(II)-rich levels, the correlation with polysaccharide amounts suggests that only part of the $\mathrm{Fe}$ (III)-rich species was organically bound and that the interaction of the microbial entities with the Fe(III)-rich species was less than that with the Fe(II)-rich species.

Comparison of the $\mathrm{Mn}$ and $\mathrm{Ni}$ maps with component maps derived from the $\mathrm{O}$ 1s image sequence (not shown) indicates that the $\mathrm{O}$ 1s signal detected in the same region was mainly polysaccharides. While the characteristic curved structure found in the $\mathrm{Ni}$ and $\mathrm{Mn}$ component maps was also seen in the oxide map, it is also seen in the maps of other oxygen-containing components and thus the oxide signal is not specific to $\mathrm{Ni}$ or $\mathrm{Mn}$ species.

Biofilm-Metal Biogeochemical Processes. We have previously shown (17) that detailed analysis of $C$ 1s image sequences provides extensive information on the biochemistry of biofilms. In this work we have focused on demonstrating the methodology for quantitative metal mapping in a complex biological system. Hence we made only limited $\mathrm{C}$ 1s measurements in this region of the biofilm and, although we do have a complete $O$ 1s image sequence, we have presented only a limited analysis of those results. Here we place the metal maps in the context of the morphological and biochemical information.

Figure 6 plots a color composite of the 4 metal species maps (Fe(II), Fe(III), Mn, Ni) superimposed on the preedge 


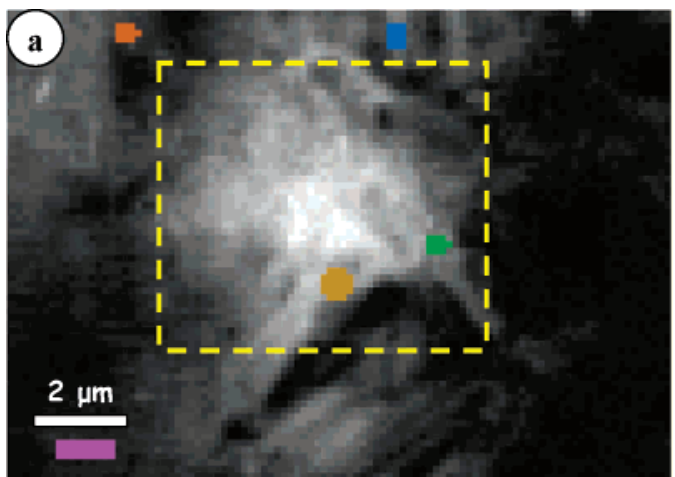

(b)

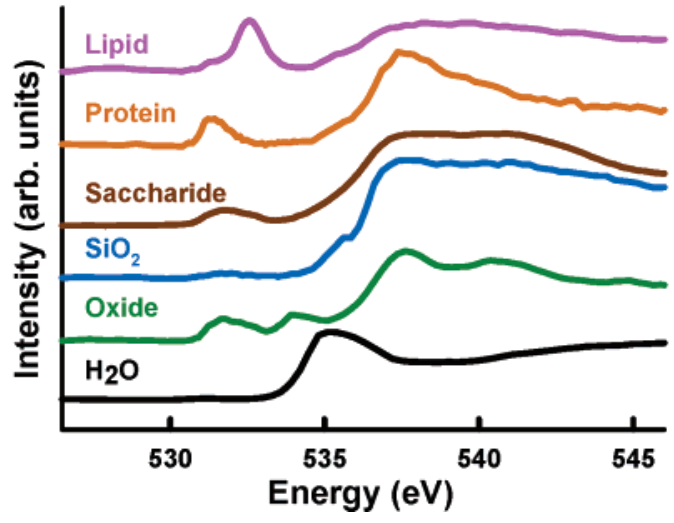

FIGURE 5. (a) Optical density map at $531.7 \mathrm{eV}$, with overlaid indicators for the locations where 0 1s spectra were extracted (blue, $\mathrm{SiO}_{2}$; green, oxide; pink, lipid; orange, protein; brown, polysaccharide). The yellow box indicates the area of the detailed metal study. (b) 0 1s X-ray absorption spectra extracted from the 0 1s image sequence of the biofilm in the indicated regions. The spectrum of $\mathrm{H}_{2} \mathrm{O}$ was recorded separately. The main species responsible for each spectrum was identified by comparison to reference spectra (unpublished).

$(282 \mathrm{eV})$ and "biology" maps $(288.2-282 \mathrm{eV})$. The preedge map shows the non-carbon material, which is mainly attributable to silica from the diatom frustules. The biological map primarily indicates the microbial entities (cells and EPS) since the difference signal is dominated by the strong protein signal at $288.2 \mathrm{eV}$. In this area of the biofilm the 4 metal species are grouped together. Polysaccharides were observed to be associated with the accumulated metals as evident from the $\mathrm{O} 1 \mathrm{~s}$ analysis of the area. Extracellular polysaccharides have been shown to sorb or entrap particulate matter such as precipitated metal sulfides and oxides $(49,50)$. Soluble metallic cations can also be sorbed directly by polysaccharides, resulting in the formation of biominerals (7). The shape of the main $\mathrm{Mn}$ accumulation was indicative of cellular material, possibility a polymer sheath or filamentous algae. Therefore, it appears that Mn was concentrated from the river water as a result of microbial activity and was not sorbed as a particulate.

The spatial distribution of the Ni was very similar to that of Mn (Figure 4), suggesting that there was a high affinity of $\mathrm{Ni}$ for Mn biominerals. $\mathrm{Mn}^{4+}$ oxides have been reported to sorb $\mathrm{Ni}^{2+}$ (47). Haack et al. (51) observed that $\mathrm{Ni}$ was sorbed by the organic constituents of the biofilm and associated biominerals of amorphous Mn oxyhydroxides. Capsular polysaccharides, the main constituent of the cyanobacterial envelope, have been shown to adsorb high amounts of $\mathrm{Mn}^{2+}$ (52). Biogenic precipitation of $\mathrm{Mn}^{2+}$ species by bacterial spores has been reported as a first step of Mn nodule formation (22). On the basis of the latter information and the apparent
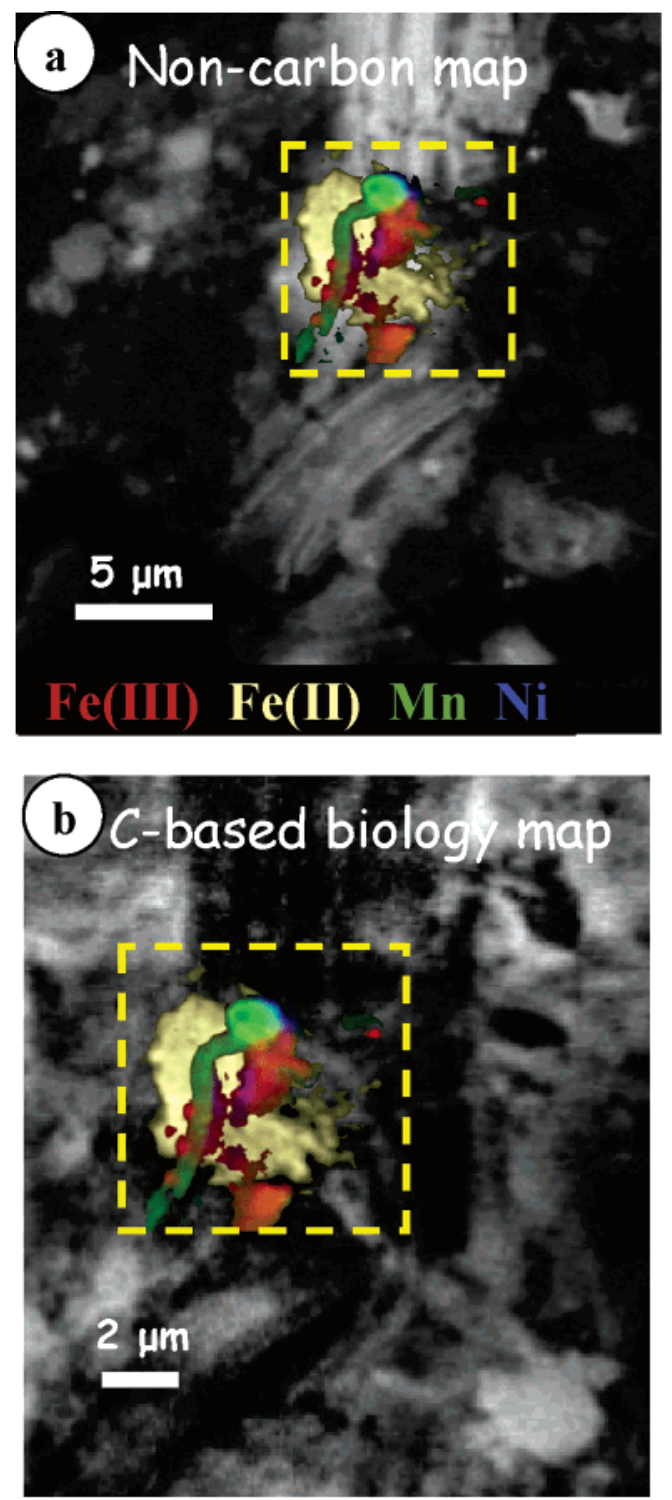

FIGURE 6. Color-coded composite map of the metal species, superimposed on (a) OD image at $282 \mathrm{eV}$ (which highlights noncarbon components), and (b) OD difference image (288.2-282 eV) (which highlights microbial entities) (pale yellow, Fe(II)-rich; red, $\mathrm{Fe}$ (III)-rich; green, $\mathrm{Mn}$; blue, $\mathrm{Ni}$; individual intensities scaled to fill each color range). The yellow dotted line indicates the area of the detailed metal study.

association of Mn with polysaccharides, it would appear that the Ni was sorbed by Mn biominerals. These results cannot tell if the Ni was sorbed directly to $\mathrm{Mn}$ or if it was sorbed by the polysaccharides associated with $\mathrm{Mn}$. It may be possible to develop a remediation strategy that takes advantage of the apparent high affinity of Ni for Mn-biofilm materials.

The shape of the Fe spatial distribution maps was more in keeping with in situ formation of the Fe material than with entrapment of an Fe particulate, although the shape does not particularly suggest that cellular components were involved in its formation. Chan et al. (7) examined the natural biominerals in an iron oxide-encrusted biofilm. Their work showed that microbially produced polysaccharides can template the nucleation of pseudo-single crystals of akaganeite (an Fe mineral). Hence, it seems likely that polysaccharides were involved in the formation of the Fe material. The markedly different spatial distributions of the Fe species compared to that of $\mathrm{Mn}$ (and Ni) indicates that at least two different types of polysaccharides were involved. The spectral 
dimension of STXM has so far not been used to differentiate between different polysaccharides. These results are consistent with the fact that different bacterial species have unique polysaccharides and wide variation in their affinity for specific metals. This biofilm was a very rich bacterialalgal community with a variety of complex architectures and microbial compositions. Thus it can be expected that there would be a variety of polysaccharides in the biofilm and that their affinity for a specific metal could be different.

The Fe(II)-rich and Fe(III)-rich species in the biofilm occur in close proximity to each other. The presence of Fe (III) is in keeping with the well aerated and high $\mathrm{pH}$ conditions of the sample, while the presence of Fe (II) is consistent with the well-known phenomenon of microbial Fe reduction that could be occurring within the biofilm $(47,53)$. However, sorption of Fe(II) to Fe(III) species cannot be ruled out (54). Although there is some uncertainty as to whether there was transformation of the Fe by the biofilm, it is clear that STXM has the capabilities to examine metal oxidation transformation processes in biofilms, as also shown in other work (22).

\section{Acknowledgments}

This work was supported by the National Water Research Institute, Environment Canada, the Advanced Foods and Materials Network, NSERC (Canada), and the Canada Research Chair program (A.P.H.). Construction and operation of the STXM5.3.2 microscope is supported by NSF DMR9975694, DOE DE-FG02-98ER45737, Dow Chemical, NSERC, and the Canadian Foundation for Innovation. We thank David Kilcoyne, the 5.3 .2 beamline scientist, for his contributions to developing and maintaining the instrument. The Advanced Light Source is supported by the Director, Office of Energy Research, Office of Basic Energy Sciences, Materials Sciences Division of the U.S. Department of Energy, under Contract DE-AC03-76SF00098.

\section{Supporting Information Available}

Text and figures describing in detail the methodology used to set the intensity scale of the reference spectra, evaluation of the methodology, and selected Fe and Mn 2p spectra from the literature. This material is available free of charge via the Internet at http://pubs.acs.org.

\section{Literature Cited}

(1) Gadd, G. M. Microbial influence on metal mobility and application for bioremediation. Geoderma 2004, 122, 109-119.

(2) Brown, M. J.; Lester, J. N. Role of bacterial extracellular polymers in metal uptake in pure bacterial culture and activated sludgeI. Water Res. 1982, 16, 1539-1548.

(3) Mittelman, M. W.; Geesey, G. G. Copper-binding characteristics of exopolymers from a freshwater-sediment bacterium. Appl. Environ. Microbiol. 1985, 49, 846-851.

(4) Lünsdorf, H.; Brümmer, I.; Timmis, K. N.; Wagner-Döbler, I. Metal selectivity of in situ microcolonies in biofilms of the Elbe River. J. Bacteriol. 1997, 179, 31-40.

(5) Bender, J.; Rodriguez-Eaton, S. U.; Ekanemesang, M.; Phillips, P. Characterization of metal-binding bioflocculants produced by the cyanobacterial component of mixed microbial mats. Appl. Environ. Microbiol. 1994, 60, 2311-2315.

(6) Liehr, S. K.; Chen, H. J.; Lin, S.-H. Metals removal by algal biofilms. Water Sci. Technol. 1994, 30, 59-60.

(7) Chan., C. S.; De Stasio, G.; Welch, S. A.; Girasole, M.; Frazer, B. H.; Nesterova, M. V.; Fakra, S.; Banfield, J. F. Microbial polysaccharides template assembly of nanocrystal fibers. Science 2004, 303, 1656-1658.

(8) Leppard, G. G.; Droppo, I. G.; West, M. M.; Liss, S. N. Compartmentalization of metals within the diverse colloidal matrixes comprising activated sludge microbial flocs. J. Environ. Qual. 2003, 32, 2100-2108.

(9) Webb, S. M.; Leppard, G. G.; Gaillard, J.-F. Zinc speciation in a contaminated aquatic environment: characterization of environmental particles by analytical electron microscopy. Environ. Sci. Technol. 2000, 34, 1926-1933.
(10) Wuertz, S.; Spaeth, R.; Hinderberger, A.; Griebe, T.; Flemming, H. C.; Wilderer, P.A. A new method for extraction of extracellular polymeric substances from biofilms and activated sludge suitable for direct quantification of sorbed metals. Water Sci. Technol. 2001, 43, 25-31.

(11) Glasauer, S.; Langley, T.; Beveridge, T. J. Intracellular iron minerals in a dissimilatory iron-reducing bacterium. Science 2002, 295, 117-119.

(12) Jackson, T. A.; Leppard, G. G. Energy-dispersive X-ray microanalysis and its applications in biogeochemical research. In Soil Mineral-Organic Matter-Microorganism Interactions and Ecosystem Health; Violante, A., Huang, P. M., Bollag, J.-M., Gianfreda, L., Eds.; Developments in Soil Science series vol. 28A; Elsevier Science: Amsterdam, 2002.; pp 219-260.

(13) Ade, H. X-ray Spectromicroscopy. In Vacuum Ultraviolet Spectroscopy II; Samson, J. A. R., Ederer, D. L., Eds.; Vol. 32 in Experimental Methods In The Physical Sciences series; Academic Press: New York, 1998; pp 225-261.

(14) Ade H.; Urquhart, S. G. NEXAFS spectroscopy and microscopy of natural and synthetic polymers. In Chemical Applications of Synchrotron Radiation; Sham, T. K., Ed.; World Scientific Publishing: Singapore, 2002; pp 285-355.

(15) Rightor, E. G.; Urquhart, S. G.; Hitchcock, A. P.; Ade, H.; Smith, A. P.; Mitchell, G. E.; Priester, R. D.; Aneja, R. D.; Appel, G.; Wilkes, G. Lidy, W. E. Identification and quantitation of urea precipitates in flexible polyurethanes by X-ray Spectromicroscopy. Macromolecules 2002, 35, 5873-5882.

(16) Hitchcock, A. P.; Morin, C.; Heng, Y. M.; Cornelius, R. M.; Brash, J. L. Towards practical soft X-ray spectromicroscopy of biomaterials. J. Biomater. Sci. Polym. Ed. 2002, 13, 919-938.

(17) Lawrence, J. R.; Swerhone, G. D. W.; Leppard, G. G.; Araki, T.; Zhang, X.; West, M. M.; Hitchcock, A. P. Scanning transmission $\mathrm{X}$-ray, laser scanning, and transmission electron microscopy mapping of the exopolymeric matrix of microbial biofilms. Appl. Environ. Microbiol. 2003, 69, 5543-5554.

(18) Gilbert, E. S.; Khlebnikov, A.; Meyer-Ilse, W.; Keasling, J. D. Use of soft X-ray microscopy for the analysis of early-stage biofilm formation. Water Sci. Technol. 1999, 39, 269-272.

(19) Van der Laan, G.; Zanene, J.; Sawatzky, G. A.; Karnatak, R.; Esteva, J. M. Comparison of X-ray absorption with X-ray photoemission of Nickel dihalides and NiO. Phys. Rev. B 1986, 33, 4253-4263.

(20) Van der Laan, G.; Kirkman, I. The 2p absorption spectra of 3d transition metal compounds in tetrahedral and octahedral symmetry. J. Phys. Condens. Matter 1992, 4, 4189-4204.

(21) Garvie, L. A. J.; Buseck, P. R. Ratios of ferrous iron from nanometer sized areas of minerals. Nature 1998, 367, 667-670.

(22) Pecher, K.; Mccubbery, D.; Kneedler, E.; Rothe, J.; Bargar, J.; Meigs, G.; Cox, L.; Nealson, K.; Tonner, B. Quantitative charge state analysis of manganese biominerals in aqueous suspension using Scanning Transmission X-ray Microscopy (STXM). Geochim. Cosmochim. Acta 2003, 67, 1089-1098.

(23) Toner, B.; Fakra, S.; Villalobos, M.; Warwick, T.; Sposito, G. Spatially resolved characterization of biogenic manganese oxide production within a bacterial biofilm. Appl. Environ. Microbiol. 2005, 71, 1300-1310.

(24) Yoon, T. H.; Johnson, S. B.; Benzerara, K.; Doyle, C. S.; Tyliszczak, T.; Shuh, D. K.; Brown, G. E., Jr. In situ characterization of aluminum-containing mineral-microorganism aqueous suspensions using scanning transmission X-ray microscopy. Langmuir 2004, 20, 10361-10366.

(25) Rothe, J.; Plaschke, M.; Denecke, M. A. Scanning transmission $\mathrm{X}$-ray microscopy as a speciation tool for natural organic molecules. Radiochim. Acta 2004, 92, 711-715.

(26) Lawrence, J. R.; Korber, D. R.; Wolfaardt, G. M.; Caldwell, D. E.; $\mathrm{Neu}, \mathrm{T}$. R. Analytical imaging and microscopy techniques. In Manual of Environmental Microbiology, 2nd ed.; Hurst, C. J., Crawford, R. L., Knudsen, G. R., McInerney, M., Stetzenbach, L. D., Eds.; American Society for Microbiology Press: Washington DC, 2002; pp 39-61.

(27) Lawrence, J. R.; Swerhone, G. D. W.; Neu, T. R. Design and evaluation of a simple rotating annular reactor for replicated biofilm studies. J. Microbiol. Methods 2000, 42, 215-224.

(28) Kilcoyne, A. L. D.; Steele, W. F.; Fakra, S.; Hitchcock, P.; Franck, K.; Anderson, E.; Harteneck, B.; Rightor, E. G.; Mitchell, G. E.; Hitchcock, A. P.; Yang, L.; Warwick, T.; Ade, H. Interferometrically controlled scanning transmission microscopes at the Advanced Light Source. J. Synchrotron Radiat. 2003, 10, 125-136.

(29) Warwick, T.; Ade, H.; Kilcoyne, A. L. D.; Kritscher, M.; Tylisczcak T.; Fakra, S.; Hitchcock, A. P.; Hitchcock, P.; Padmore, H. A. A new bend magnet beam line for scanning transmission X-ray microscopy at the Advanced Light Source.J. Synchrotron Radiat. 2002, 9, 254-257. 
(30) Bluhm, H.; Andersson, K.; Araki, T.; Benzerara, K.; Brown, G. E.; Dynes, J. J.; Ghosal, S.; Gilles, M. K.;. Hansen, H.-Ch.; Hemminger, J. C.; Hitchcock, A. P.; Ketteler, G.; Kneedler, E.; Lawrence, J. R.; Leppard, G. G.; Majzlam, J.; Mun, B. S.; Myneni, S. C. B.; Nilsson, A.; Ogasawara, H.; Ogletree, D. F.; Pecher, K.; Salmeron, M.; Tonner, B.; Tyliszczak, T.; Yoon, T. H.; Shuh, D. K. Soft X-ray microscopy and spectroscopy at the Molecular Environmental Science Beamline at the Advanced Light Source. J. Electron Spectrosc. 2005, 150, 86-104.

(31) Jacobsen, C.; Wirick, S.; Flynn, G.; Zimba, C. Soft X-ray spectroscopy from image sequences with sub-100 nm spatial resolution. J. Microsc. 2000, 197, 173-184.

(32) Hitchcock, A. P.; Morin, C.; Zhang, X.; Araki, T.; Dynes, J. J.; Stover, H.; Brash, J. L,; Lawrence, J. R.; Leppard, G. G. Soft X-ray spectromicroscopy of biological and synthetic polymer systems. J. Electron Spectrosc. Relat. Phenom. 2005, 144-147, 259-269.

(33) Koprinarov, I. N.; Hitchcock, A. P.; McCrory, C. T.; Childs, R. F. Quantitative mapping of structured polymeric systems using singular value decomposition analysis of soft X-ray images. J. Phys. Chem. B 2002, 106, 5358-5364.

(34) aXis2000 is written in Interactive Data Language (IDL). It is available free for noncommercial use from http://unicorn.mcmaster.ca/aXis2000.html.

(35) Kneedler, E. M.; Rothe, J.; Weissmahr, K. W.; Pecher, K.; Tonner, B. P. Identification of green rust in environmental compounds using XANES of Fe- $\mathrm{L}_{\mathrm{II}}$ III edges. In Advanced Light Source Annual Compendium of Abstracts; Lawrence Berkeley Publications, 1997.

(36) Vinogradov, A. S.; Preobrajenski, A. B.; Krasnikov, S. A.; Chassé, T.; Szargan, R.; Knop-Gericke, A.; Schlögl, R.; Bressler, P. X-ray absorption evidence for the back-donation in iron cyanide complexes. Surf. Rev. Lett. 2002, 9, 359-364.

(37) Brown, G. E., Jr., private communication, 2005.

(38) Mikhlin, Y.; Tomashevich, Y.; Vyalikh, D.; Zhang, L. XANES studies of chemically modified surface layers of metal sulphides. In Bessy Annual Report; Berliner Elektronenspeicherring-Gesellschaft für Synchrotronstrahlung m.b.H. (BESSY): Berlin, Germany, 2003; pp 113-115.

(39) Peng, G.; van Elp, J.; Jang, H.; Que, L., Jr.; Armstrong, W. H.; Cramer, S. P. L-Edge X-ray absorption and X-ray magnetic circular dichroism of oxygen-bridged iron complexes. J. Am. Chem. Soc. 1995, 117, 2515-2519.

(40) Kuiper, P.; Searle, B. G.; Rudolf, P.; Tjeng, L. H.; Chen, C. T. X-ray magnetic dichroism of antiferromagnet $\mathrm{Fe}_{2} \mathrm{O}_{3}$ : The orientation of magnetic moments observed by $\mathrm{Fe} 2 \mathrm{p}$ X-ray absorption spectroscopy. Phys. Rev. Lett. 1993, 70, 15491552.
(41) Water Quality Department, City of Saskatoon, Saskatoon, Saskatchewan, Canada, personal communication.

(42) Henke, B. L.; Gullikson, E. M.; Davis, J. C. At. Data Nucl. Data Tables 1993, 54, 181-297.

(43) CRC Handbook of Chemistry and Physics, 60th ed.; Weast, R. C., Ed.; CRC Press: Boca Raton, FL, 1980.

(44) Twining, B. S.; Baines, S. B.; Fisher, N. S.; Maser, J.; Vogt, S.; Jacobsen, C.; Tovar-Sanchez, A.; Sañudo-Wilhelmy, S. A Quantifying trace elements in individual aquatic protest cells with a synchrotron X-ray fluorescence microprobe. Anal. Chem. 2003, 3805-3816

(45) Waychunas, G. private communication, 2004. http://wwwesd.lbl.gov/GEO/ aqueous_geochem/syncbased_valencestate.html.

(46) Chen, C. T.; Sette, F. High-resolution soft X-ray spectroscopies with the Dragon beamline. Phys. Scr. 1990, 119-126.

(47) Ehrlich, H. L. Geomicrobiology, 4th Ed.; Marcel Dekker: New York, 2002; pp 1-767.

(48) deGroot, F.; Grioni, M.; Fuggle, J.; Ghijsen, J.; Sawatzky, G.; Petersen, H. Oxygen 1s X-ray absorption spectroscopy of transition metal oxides. Phys. Rev. B 1989, 40, 5715-5723.

(49) Flemming, H.-K. Sorption sites in biofilms. Water Sci. Technol. 1995, 32, 27-33.

(50) Vieira, M. J.; Melo, L. F. Effect of clay particles on the behaviour of biofilms formed by Pseudomonas fluorescens. Water Sci. Technol. 1995, 32, 45-52.

(51) Haack E. A.; Warren, L. A. Biofilm hydrous manganese oxyhydroxides and metal dynamics in acid rock drainage. Environ. Sci. Technol. 2003, 37, 4138-4147.

(52) Mohamend, Z. Removal of cadmium and manganese by a nontoxic strain of the freshwater Cyanobacterium Gloeothece magna. Water Res. 2001, 35, 4405-4409.

(53) Cowen, J. P.; Silver, M. W. The association of iron and manganese with bacteria on marine macroparticulate material. Science 1984, 224, 1340-1342.

(54) Roden, E. E.; Urrutia, M. M. Ferrous iron removal promotes microbial reduction of crystalline iron(III) oxides. Environ. Sci. Technol. 1999, 33, 1847-1853.

Received for review July 13, 2005. Revised manuscript received December 20, 2005. Accepted December 20, 2005.

ES0513638 